\section{Congratulatory Comment}

\section{Check for updates}

\title{
Congratulatory comment from Health and Welfare Committee of the National Assembly
}

\author{
Myung-su Lee
}

Chairman of the Health and Welfare Committee of the National Assembly Chairman of the Korean Parliamentarian Forum on Global Health

I would like to begin by expressing my sincere congratulations on the publication of the first issue of the Journal of Global Health Science (JGHS), which aims to share global health research conducted by domestic and foreign researchers.

under the terms of the Creative Commons Attribution Non-Commercial License (https:// creativecommons.org/licenses/by-nc/4.0/) which permits unrestricted non-commercial use, distribution, and reproduction in any medium, provided the original work is properly cited.

(c) 2019 Korean Society of Global Health. This is an Open Access article distributed
The importance of "Global Health Studies" has increased in the era of globalization, as the health issues that impact one nation are not strictly limited by national borders and can impact the whole world.

Responding to this new reality, the Korean Parliamentarian Forum on Global Health (KPFGH) was established in 2015, for the purpose of promoting international exchange and cooperation related to legislative, policy, and budgetary action in the health and medical sector. Additionally, in 2016, Korean parliamentarians expanded the campaign by creating the "Asia-Pacific Global Health Parliamentarian Forum." The forum aims to build international cooperation between legislative bodies in order to solve global health issues of the Asia-Pacific region.

The Korean Society of Global Health (KSGH) and the KPFGH are complementary to each other, with the KPFGH supporting research conducted by the KSGH. Benefitting from the accomplishments of the research conducted by the KSGH, the KPFGH promotes legislative activities and increased exchanges and cooperation between parliamentarians.

South Korea's first Global Health Academic Journal highlights the global health accomplishments of both domestic and foreign researchers and hopes to contribute to the development of Global Health Studies by facilitating productive discussions between stakeholders from not only academia and the medical sector, but from international organizations, bi-lateral development cooperation agencies, and civil society as well.

I express my appreciation to the global health researchers who continue to apply their efforts towards making a healthier world. I also wish the JGHS every success and hope that forthcoming academic discussions will substantially contribute to the promotion of global health.

Once again, I wish to express my sincere congratulations on the publication of the first issue of the JGHS. I hope for its continued development and success. 